\title{
Diagnosing Cardiovascular Autonomic Neuropathy in Type 2 Diabetic Patients with Subacute ST Elevation Myocardial Infarction
}

DOI: $10.17691 / \mathrm{stm} 2016.8 .2 .07$

Received October 31, 2015

A.V. Bushuyeva, PhD Student, Department of Endocrinology and Internal Diseases";

S.N. Botova, MD, PhD, Tutor, Department of Endocrinology and Internal Diseases";

I.G. Pochinka, MD, PhD, Associate Professor, Department of Endocrinology and Internal Diseases';

E.P. Morozova, MD, PhD, Associate Professor, Department of Endocrinology and Internal Diseases

A.A. Frolov, Interventional Surgeon, Department of Endovascular Surgery;

L.G. Strongin, MD, DSc, Professor, Head of the Department of Endocrinology and Internal Diseases ${ }^{1}$

${ }^{1}$ Nizhny Novgorod State Medical Academy, 10/1 Minin and Pozharsky Square, Nizhny Novgorod, 603005,

Russian Federation;

${ }^{2}$ City Clinical Hospital No.13, 51 Patriotov St., Nizhny Novgorod, 603018

The aim of the investigation is to develop criteria for diagnosing cardiovascular autonomic neuropathy in patients with type 2 diabetes mellitus (DM2) in the sub-acute stage of ST-elevation myocardial infarction (STEMI).

Materials and Methods. The study involved 54 patients with STEMI without previous coronary history, who underwent reperfusion therapy, among them 27 patients suffered from DM2 (group 1), 27 individuals had no carbohydrate metabolism disorders (group 2). Group 3 consisted of 23 DM2 patients without cardiovascular pathology. All patients had sinus rhythm.

Five Ewing's cardiovascular reflex tests were performed on day 10-14 after STEMI development. The heart rate variability was analyzed using a five-minute electrocardiogram recording. The following values were calculated: standard deviation of NN intervals, total spectrum power, and scatterogram parameters: the length of the "cloud", its width and area.

Results. The study of heart rate variability by scatterogram analysis has proved to be preferable for diagnosing cardiovascular autonomic neuropathy in patients with DM2 and the subacute stage of STEMI.

Conclusion. A criterion for the presence of diabetic cardiovascular autonomic neuropathy is the scatterogram "cloud" area value $\mathrm{S} \leqslant 571 \mathrm{~ms}^{2}$. This criterion can be used to diagnose the disease in the population of DM2 patients with a sub-acute stage of myocardial infarction.

Key words: cardiovascular autonomic neuropathy; diabetes mellitus; myocardial infarction.

The combination of type 2 diabetes mellitus (DM2) and ST-elevation myocardial infarction (STEMI) on electrocardiogram is a frequent syndrome. 22 to $25 \%$ of STEMI patients suffer from DM2 [1, 2]. Diabetic neuropathy including cardiovascular autonomic neuropathy (CAN) is a widespread complication of diabetes mellitus [3]. The incidence rate of CAN in different studies varies from 34 to $90 \%$ depending on the applied diagnosis criteria and the category of patients under study [4, 5]. The presence of CAN adversely affects the prognosis for DM2 patients who have suffered myocardial infarction. Their mortality rate is significantly higher [6].

Cardiovascular reflex tests devised by Ewing in 1975 and approved at the conference on diabetic neuropathy held in San-Antonio (1988) are traditionally used to diagnose CAN [7-9]. However, these tests are performed under the condition that patients have no myocardial infarction $[10,11]$. In recent years heart rate variability (HRV) has been analyzed to diagnose CAN in diabetic patients. This method offers the possibility to reveal CAN at the pre-clinical stage. The signs of CAN presence are considered to be the following: decline in the spectrum power in all frequency ranges, the absence of low-frequency spectrum component increment when standing up, abnormal decrease in total spectrum power, reduction of length and area of the scatterogram "cloud" [12]. However, such changes in the described tests are also characteristic of patients with myocardial infarction [13-15]. A similar CAN diagnosis problem has also existed in patients with a combination of DM and chronic cardiac failure. Earlier the authors have suggested a criterion for diagnosing CAN in such patients using time-domain HRV analysis and assessment of standard deviation of NN intervals (SDNN). The value of SDNN $<33 \mathrm{~ms}$ was offered as a criterion of CAN presence [16]. However, patients with myocardial infarction were not included in the study,

For contacts: Svetlana N. Botova, e-mail: e-mail: sve-botova@yandex.ru 
therefore the criterion of $\mathrm{SDNN}<33 \mathrm{~ms}$ could not be used for completing our task, namely, diagnosing CAN in DM2 patients with myocardial infarction.

The aim of the investigation was to develop criteria for diagnosing cardiovascular neuropathy in patients with type 2 diabetes mellitus in the subacute stage of ST-elevation myocardial infarction.

Materials and Methods. The study involved 77 individuals including 54 patients with STEMI without previous coronary history. Among them 27 patients suffered from DM2 (group 1), 27 individuals had no carbohydrate metabolism disorders (group 2), while group 3 comprised 23 DM2 patients without cardiovascular pathology. All STEMI patients underwent reperfusion therapy (primary percutaneous coronary intervention, thrombolytic therapy followed by coronary intervention or isolated thrombolytic therapy).
The study was performed on day 10-14 after the onset of STEMI symptoms. The study complies with the Declaration of Helsinki (adopted in June 1964 (Helsinki, Finland) and revised in October 2000 (Edinburgh, Scotland)) and was performed following approval by the Ethics Committee of Nizhny Novgorod State Medical Academy. Written informed consent was obtained from every patient.

The patients in the groups did not differ in age and sex. Groups 1 and 2 had no significant differences in the localization of myocardial infarction, reperfusion therapy methods, the maximum recorded troponin level, cardiac failure severity, values of left ventricular ejection fraction. All patients of groups 1 and 2 received standard therapy for myocardial infarction: reperfusion therapy, antithrombotic drugs, statins, angiotensin-converting enzyme inhibitors, beta-blockers (Table 1).

Table 1

The characteristics of patients under study

\begin{tabular}{|c|c|c|c|c|}
\hline Index & $\begin{array}{l}\text { Group } 1 \text { - STEMI } \\
\text { with DM2 }(n=27)\end{array}$ & $\begin{array}{l}\text { Group } 2 \text { - STEMI } \\
\text { without DM2 }(n=27)\end{array}$ & $\begin{array}{c}\text { Group } 3-\text { DM2 } \\
\text { without STEMI }(n=23)\end{array}$ & $p$ \\
\hline Age (years) $(M \pm S t d)$ & $61.5 \pm 6.9$ & $60.8 \pm 6.8$ & $59.5 \pm 5.7$ & 0.32 \\
\hline $\begin{array}{l}\text { Sex (\%/absolute number): } \\
\text { males } \\
\text { females }\end{array}$ & $\begin{array}{l}44 / 12 \\
56 / 15\end{array}$ & $\begin{array}{l}52 / 14 \\
48 / 13\end{array}$ & $\begin{array}{c}26 / 6 \\
74 / 17\end{array}$ & 0.26 \\
\hline $\begin{array}{l}\text { Localization of myocardial infarction (\%/absolute number } \\
\text { anterior } \\
\text { inferior } \\
\text { other localization }\end{array}$ & $\begin{array}{c}33 / 9 \\
52 / 14 \\
15 / 4\end{array}$ & $\begin{array}{c}40 / 11 \\
48 / 13 \\
12 / 3\end{array}$ & - & 0.58 \\
\hline $\begin{array}{l}\text { Revascularization (\%/ absolute number): } \\
\text { isolated thrombolysis } \\
\text { primary percutaneous coronary intervention } \\
\text { thrombolysis + percutaneous coronary intervention }\end{array}$ & $\begin{array}{c}18.5 / 5 \\
37 / 10 \\
44.5 / 12\end{array}$ & $\begin{array}{c}14.8 / 4 \\
29.6 / 8 \\
56 / 15\end{array}$ & - & 0.72 \\
\hline $\begin{array}{l}\text { Coronary bed lesion (\%/absolute number): } \\
\text { single-vessel } \\
\text { two-vessel } \\
\text { three-vessel }\end{array}$ & $\begin{array}{c}16 / 4 \\
36 / 10 \\
48 / 13\end{array}$ & $\begin{array}{l}37 / 10 \\
26 / 7 \\
37 / 10\end{array}$ & - & 0.13 \\
\hline Maximum recorded troponin I level (ng/ml) (Me [25; 75]) & $27.2[12.7 ; 45.3]$ & $31.4[21.8 ; 50]$ & - & 0.5 \\
\hline The GRACE score (Me $[25 ; 75])$ & $109[103 ; 125]$ & $107[94 ; 115]$ & - & 0.33 \\
\hline Ejection fraction (\%) (Me [25; 75]) & $48[45 ; 58]$ & $51[48 ; 58]$ & - & 0.22 \\
\hline $\begin{array}{l}\text { Killip class (\%/absolute number): } \\
\text { I } \\
\text { II } \\
\text { III } \\
\text { IV }\end{array}$ & $\begin{array}{c}62 / 17 \\
30 / 8 \\
4 / 1 \\
4 / 1\end{array}$ & $\begin{array}{c}66 / 18 \\
26 / 7 \\
4 / 1 \\
4 / 1\end{array}$ & - & 0.86 \\
\hline $\begin{array}{l}\text { RSCS (rating scale of clinical state) class (\%/absolute nu } \\
\text { I functional class } \\
\text { II functional class }\end{array}$ & $\begin{array}{l}33 / 9 \\
67 / 18\end{array}$ & $\begin{array}{l}48 / 13 \\
52 / 14\end{array}$ & - & 0.21 \\
\hline $\begin{array}{l}\text { Therapy (\%/absolute number): } \\
\text { diet } \\
\text { insulin } \\
\text { oral antidiabetic drugs } \\
\text { combined }\end{array}$ & $\begin{array}{c}11 / 3 \\
19 / 5 \\
59 / 16 \\
11 / 3\end{array}$ & - & $\begin{array}{c}4 / 1 \\
39 / 9 \\
35 / 8 \\
22 / 5\end{array}$ & 0.16 \\
\hline
\end{tabular}


The study included no patients with recurrent myocardial infarction, non-ST-elevation myocardial infarction on electrocardiogram, those who did not undergo reperfusion treatment (systemic thrombolysis, percutaneous coronary intervention), patients with atrial fibrillation and persons above 75 years of age. Past medical history of all patients was taken, and physical examination carried out.

Myocardial infarction characteristics were analyzed using several parameters. The extent of cardiac injury was assessed by the value of maximum recorded troponin level, prognostic infarction characteristics were estimated by GRACE score, Killip classification was used to identify cardiac failure severity. On day 10-14 after STEMI development all patients underwent five Ewing's cardiovascular reflex tests (heart rate changes with deep slow breathing, Valsava test, Schellong postural test, 30:15 test, isometric exercise test). When assessing the results, the criteria suggested by Ewing [5] in Vinik's modification [17] were used. Each test was assessed as 0 scores, if indexes were normal, 1 score was given for borderline indexes, 2 scores for pathological indexes.

HRV was studied using Polyspectrum-Rhythm device (Neurosoft, Russia). The following indexes were calculated: SDNN - standard deviation of NN intervals, total spectrum power and scatterogram values: the length of the "cloud", its width and area.

The data were statistically processed using Statistica 8.0 software package (StatSoft Inc., USA).

Results and Discussion. When analyzing cardiovascular reflex tests and time-domain HRV analysis the signs of damage to autonomic nervous system were revealed in the groups of patients with subacute myocardial infarction irrespective of diabetes mellitus presence, there was no statistically significant difference between the groups. At the same time HRV assessment by correlational rhythmography method (Poincaré plot) showed significantly lower indexes in patients with a combination of diabetes mellitus and subacute myocardial infarction (Table 2). This fact can be interpreted by CAN present in a number of patients from this group.

Among HRV parameters the scatterogram "cloud" area index demonstrated the greatest relative difference in the groups, therefore it was decided to use this parameter while developing CAN diagnosis criteria. For this purpose further investigation was carried out only in group 1 (STEMI with DM2).

Cluster analysis was performed according to the results of the parameter characterizing the extent of myocardial injury (the maximum recorded troponin level) and HRV index (the scatterogram "cloud" area). This group appeared to be heterogeneous: there were identified two clusters with no significant differences in myocardial injury index, yet HRV parameters were significantly different. Thus, in cluster 1 (18 patients), the "cloud" area median amounted to $358 \mathrm{~ms}^{2}$ (interquartile range was $185-419$, the minimum -53 , the maximum - 460), in cluster 2 (9 individuals), the median was $746 \mathrm{~ms}^{2}$ (interquartile range $680-812$; the minimum -574 , the maximum $-1,500$ ); $p<0.001$. Significance of differences was calculated using MannWhitney method (Figure 1).

Heterogeneity revealed in the group of patients with STEMI and DM2 cannot be caused by STEMI severity as there were no significant differences in STEMI characteristics between the clusters (Table 3 ).

It can be suggested that the difference in HRV indexes between the clusters is caused by the effect of CAN presence in patients of cluster 1. In this case the reference value of the "cloud" area for diagnosing CAN in patients with sub-acute MI ranges from 460 to $574 \mathrm{~ms}^{2}$ (the maximal level in patients of cluster 1 and the minimal one in those from cluster 2).

To choose the accurate criterion for CAN diagnosis (by correlation rhythmography parameters) we used ROCcurve analysis - true-positive (sensitivity) and falsepositive level (1-specificity) diagram. ROC-curve analysis allows us to differentiate disease from the norm [18].

Table 2

Indexes of cardiovascular reflex tests and heart rate variability in patients with subacute myocardial infarction with and without diabetes mellitus (Me [25; 75])

\begin{tabular}{|c|c|c|c|}
\hline Index & $\begin{array}{l}\text { Group } 1 \text { - STEMI } \\
\text { with DM2 }(n=27)\end{array}$ & $\begin{array}{c}\text { Group } 2 \text { - STEMl without } \\
\text { DM2 ( } n=27)\end{array}$ & $p$ \\
\hline Total cardiovascular reflex test score & $4[2.5 ; 5]$ & $4[2 ; 4]$ & 0.34 \\
\hline Total spectrum power $\left(\mathrm{ms}^{2}\right)$ & $245[117 ; 488]$ & $427[248 ; 652]$ & 0.04 \\
\hline SDNN (ms) & $16[12 ; 28]$ & $21[17 ; 27]$ & 0.15 \\
\hline "Cloud" length (ms) & $38[29 ; 45]$ & $56[45 ; 75]$ & $<0.001$ \\
\hline "Cloud" width (ms) & $15[9 ; 21]$ & $21[14 ; 26]$ & $<0.001$ \\
\hline "Cloud" area $\left(\mathrm{ms}^{2}\right)$ & $419[206 ; 683]$ & $861[475 ; 1466]$ & $<0.001$ \\
\hline
\end{tabular}

$\mathrm{N}$ o t e. Statistical significance of value differences was calculated by Mann-Whitney method. 


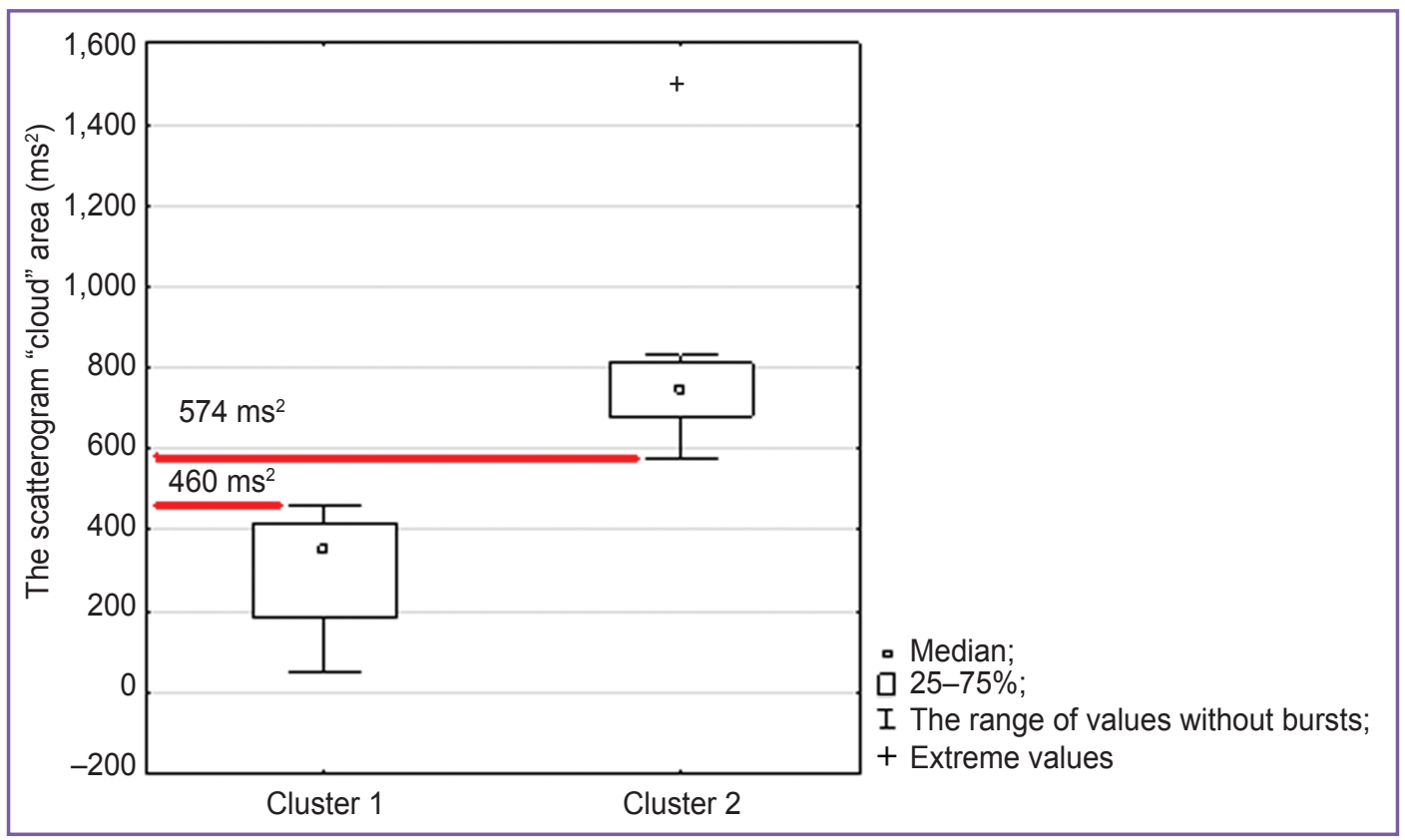

Figure 1. The "cloud" area index in clusters of diabetic mellitus patients with sub-acute myocardial infarction (group 1)

Table 3

Myocardial infarction characteristics in patients of two clusters with subacute myocardial infarction and diabetes mellitus

\begin{tabular}{|c|c|c|c|}
\hline Index & Cluster 1 (n=18) & Cluster 2 ( $n=9)$ & $p$ \\
\hline Maximum recorded troponin level (ng/ml) (Me [25; 75]) & $28.0[15.5 ; 47.6]$ & $32.0[9.9 ; 41.0]$ & 0.8 \\
\hline The GRACE risk score (Me [25; 75]) & $112[105 ; 122]$ & $112[104 ; 132]$ & 0.7 \\
\hline $\begin{array}{l}\text { Coronary bed lesion (\%/absolute number): } \\
\text { single-vessel } \\
\text { two-vessel } \\
\text { three-vessel }\end{array}$ & $\begin{array}{l}17 / 3 \\
33 / 6 \\
50 / 9\end{array}$ & $\begin{array}{l}22 / 2 \\
22 / 2 \\
56 / 5\end{array}$ & 0.69 \\
\hline $\begin{array}{l}\text { Killip class (\%/ absolute number): } \\
\text { III } \\
\text { IV }\end{array}$ & $\begin{array}{c}72 / 13 \\
22 / 4 \\
6 / 1 \\
0 / 0\end{array}$ & $\begin{array}{c}53 / 5 \\
33 / 3 \\
0 / 0 \\
11 / 1\end{array}$ & 0.34 \\
\hline
\end{tabular}

N o t e. Statistical significance of value differences was calculated by Mann-Whitney method, to evaluate the significance of proportion differences Pearson's $X$-square test was used.

For this purpose in patients of group 3 (those without limitations to undergo cardiovascular reflex tests) CAN diagnosis was first made according to cardiovascular test results (the gold standard) using Ewing and Vinik's criteria [15]. Then the results were compared to the studied test (determining the scatterogram "cloud" area).

As a result of ROC curve analysis there was obtained a criterion having the optimal ratio of sensitivity and specificity as compared to the gold standard of CAN diagnosis: the "cloud" area, $\mathrm{S} \leqslant 571 \mathrm{~ms}^{2}$ (Figure 2).
To obtain the numeric value of clinical significance of the test the area under the ROC curve was calculated which amounted to 0.867 [0.661-0.971], $p<0.001$. According to the expert value scale, this value corresponded to a very good quality of the suggested criterion.

The index value of $\mathrm{S} \leqslant 571 \mathrm{~ms}^{2}$ obtained in the cohort of diabetic patients without cardiovascular pathology and verified by cardiovascular tests pertains to the range of reference values for diagnosing CAN (460-574 $\left.\mathrm{ms}^{2}\right)$ identified by cluster analysis in group 1 (See Figure 1). 
Figure 2. ROC curve of the studied test for cardiovascular autonomic neuropathy

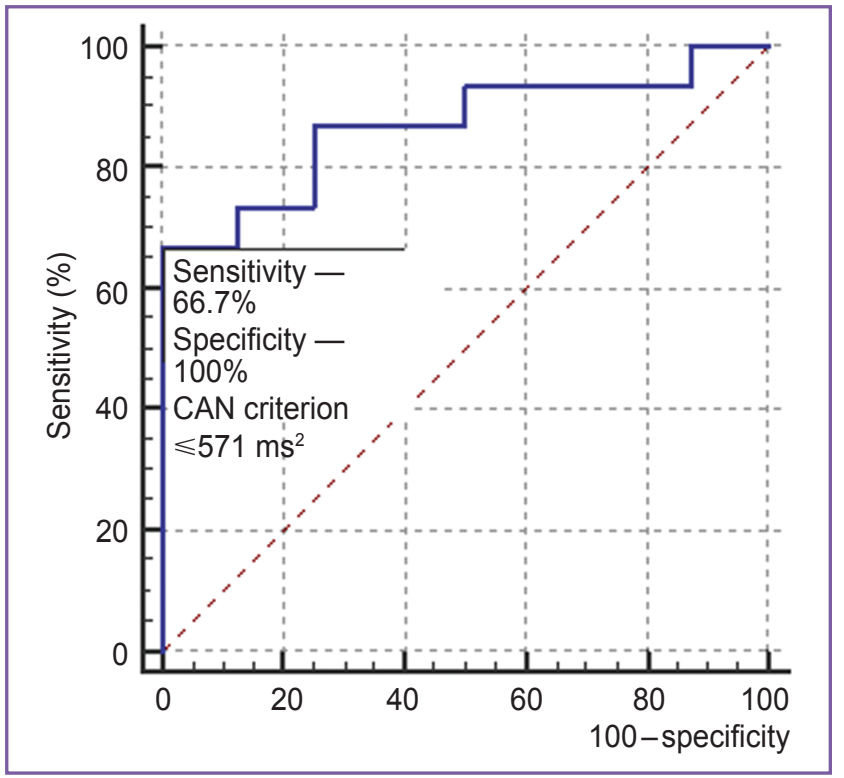

Thus, the value of $S \leqslant 571 \mathrm{~ms}^{2}$ can be considered a criterion for diagnosing cardiovascular autonomic neuropathy in DM2 patients with sub-acute myocardial infarction.

Conclusion. To diagnose cardiovascular neuropathy in patients with type 2 diabetes mellitus and the subacute phase of ST-elevation myocardial infarction on electrocardiogram it is preferable to study heart rate variability by variation scatterogram method. A criterion for diabetic cardiovascular neuropathy presence is the scattergram "cloud" area value $\mathrm{S} \leqslant 571 \mathrm{~ms}^{2}$. This criterion can be used to diagnose the disease in the population of type 2 diabetic patients with subacute myocardial infarction.

Study Funding and Conflicts of Interest. This study was not supported by any financial sources, and there is no conflicts of interest associated with this study.

\section{References}

1. Peterson E.D., Roe M.T., Chen A.Y., Fonarow G.C., Lytle B.L., Cannon C.P., Rumsfeld J.S. The NCDR ACTION Registry-GWTG: transforming contemporary acute myocardial infarction clinical care. Heart 2010; 96(22): 1798-1802, http:// dx.doi.org/10.1136/hrt.2010.200261.

2. McManus D.D., Gore J., Yarzebski J., Spencer F., Lessard D., Goldberg R.J. Recent trends in the incidence, treatment, and outcomes of patients with STEMI and NSTEMI. Am J Med 2011; 124(1): 40-47, http://dx.doi.org/10.1016/j. amjmed.2010.07.023.

3. Pop-Busui R. Cardiac autonomic neuropathy in diabetes: a clinical perspective. Diabetes Care 2010; 33(2): 434-441, http://dx.doi.org/10.2337/dc09-1294.

4. Vinik A.I., Erbas T. Diabetic autonomic neuropathy. Handb Clin Neurol 2013; 117: 279-294, http://dx.doi. org/10.1016/B978-0-444-53491-0.00022-5.

5. Tesfaye S., Boulton A.J., Dyck P.J., Freeman R., Horowitz M., Kempler P., Lauria G., Malik R.A., Spallone V.,
Vinik A., Bernardi L., Valensi P.; Toronto Diabetic Neuropathy Expert Group. Diabetic neuropathies: update on definitions, diagnostic criteria, estimation of severity, and treatments. Diabetes Care 2010; 33(10): 2285-2293, http://dx.doi. org/10.2337/dc10-1303.

6. Vujosevic S., Zamaklar M., Belada N., Stamatovic S. Mortality after acute myocardial infarction: significance of cardiovascular diabetic autonomic neuropathy (CDAN). Med Arch 2012; 66(5): 296-299, http://dx.doi.org/10.5455/ medarh.2012.66.296-299.

7. Ewing D.J., Campbell I.W., Murray A., Neilson J.M., Clarke B.F. Immediate heart-rate response to standing: simple test for autonomic neuropathy in diabetes. Br Med J 1978; 1(6106): 145-147, http://dx.doi.org/10.1136/bmj.1.6106.145.

8. American Diabetes Association American Academy of Neurology. Consensus statement: report and recommendations of the San Antonio conference on diabetic neuropathy. Diabetes Care 1988; 37: 1000-1004, http://dx.doi. org/10.2337/diacare.11.7.592.

9. Ewing D.J., Campbell I.W., Clarke B.F. The natural history of diabetic autonomic neuropathy. Q J Med 1980; 49(193): 95-108.

10. Vinik A.I., Maser R.E., Mitchell B.D., Freeman R. Diabetic autonomic neuropathy. Diabetes Care 2003; 26(5): 1553-1579, http://dx.doi.org/10.2337/diacare.26.5.1553.

11. Bondar' I.A., Demin A.A., Koroleva E.A. Diabeticheskaya avtonomnaya neyropatiya [Diabetic autonomic neuropathy]. Novosibirsk: Izdatel'stvo NGTU, 2006.

12. Guzik P., Piskorski J., Krauze T., Schneider R., Wesseling K.H., Wykretowicz A., Wysocki H. Correlations between the Poincaré plot and conventional heart rate variability parameters assessed during paced breathing. $J$ Physiol Sci 2007; 57(1): 63-71, http://dx.doi.org/10.2170/ physiolsci.rp005506.

13. Huikuri H.V., Stein P.K. Heart rate variability in risk stratification of cardiac patients. Prog Cardiovasc Dis 2013; 6(2): 153-159, http://dx.doi.org/10.1016/j.pcad.2013.07.003.

14. Buccelletti E., Gilardi E., Scaini E., Galiuto L., Persiani R., Biondi A., Basile F., Silveri N.G. Heart rate variability and myocardial infarction: systematic literature review and 
metanalysis. Eur Rev Med Pharmacol Sci 2009; 13(4): 299-307.

15. Bilchick K.C., Berger R.B. Prognostic value of HRV in myocardial infarction and heart failure. $J$ Cardiovasc Electrophysiol 2006; 17(6): 691-694.

16. Strongin L.G., Botova S.N., Pochinka I.G. Sposob diagnostiki kardiovaskulyarnoy avtonomnoy neyropatii u bol'nykh sakharnym diabetom, stradayushchikh khronicheskoy serdechnoy nedostatochnost'yu [The diagnostic method of cardiovascular autonomic neuropathy in diabetic patients with chronic heart failure]. Patent RF 2336811. 2008.

17. Vinik A.l., Erbas T. Recognizing and treating diabetic autonomic neuropathy. Cleve Clin J Med 2001; 68(11): 928944, http://dx.doi.org/10.3949/ccjm.68.11.928.

18. Fawcett $T$. An introduction to ROC analysis. Pattern Recognition Letters 2006; 27(8): 861-874, http://dx.doi. org/10.1016/j.patrec.2005.10.010. 